\title{
Hydrocarbon Exploration by Optimal Cross Spread Techniques, and Permit Problems in Nigeria, Semblances in Sudan, Ethiopia
}

\author{
${ }^{1}$ OSANEBI, CL; ${ }^{* 2} \mathrm{MADU}, \mathrm{AJC}$ \\ ${ }^{I}$ Seismology Department, Chinese National Petroleum Corporation BGP/CNPC, Banana Island, V/I, Lagos, Nigeria \\ *2Department of Physics, Faculty of Sciences, Federal University Otuoke (FUO), Bayelsa State, Nigeria \\ *Corresponding Author Email: ajchinenyezem07@yahoo.com
}

\begin{abstract}
One sure method for hydrocarbon exploration is the use of orthogonal geometries, in cross spread techniques. The configuration is based on consistent orthogonal pattern of both receiver lines and source lines. In areas where infrastructural facilities abound and interfere with seismic lines as obstacles, suitable designs of offsets, laminar or lateral types are employed to bypass the obstacles. The angle of excursion of the skirting from the main seismic line should be between $17^{\circ}$ and $34^{\circ}$. Around the intersection of lines with obstacles a skirting designed about the structure will maintain the source or receiver line spacing in multiples of the original line spacing. Densification of sources are used to recover the near-offset shots and near-mid offsets shots to upgrade the subsurface coverage that will compensate for the gap created by the omission of the obstacles. Compensation source line offsets, are designed as "skirting" around obstacles. This may result in drop in multiplicity or "fold of coverage "due to loss of Nears- and Near-mid CDP bins. Permit problems from host communities to the recording data acquisition is notable in this technique. The severity of the challenges partly varies with the extent of negative impact to the host communities or environment. Certain exploration activities adversely impact on the host communities and their sources of livelihood. The situation was different and in Ethiopia some years ago due to stiff opposition of the Ogaden basin youths in the coastal Somalian Region to Ethiopian Federal Government efforts on hydrocarbon exploration and development.
\end{abstract}

\section{DOI: https://dx.doi.org/10.4314/jasem.v23i3.4}

Copyright: Copyright (C) 2019 Osanebi and Madu. This is an open access article distributed under the Creative Commons Attribution License (CCL), which permits unrestricted use, distribution, and reproduction in any medium, provided the original work is properly cited.

Dates: Received: 05 February 2019; Revised: 22 March 2019; Accepted 29 March 2019

Keywords: Orthogonal lines, skirting, permit problems.

Straight and wavy source lines consistently in orthogonal geometry with the receiver lines maintained the cross spread technique from the origin of seismic lines to the end of the lines. The target of obtaining proper imaging of the subsurface also creates accesses that enhance traffic within the spread. The uninterrupted traverse and easy roll along of recording swaths are absent in the brick-wall method of seismic data acquisition, as the discrete segments of source lines terminate between receiver lines. The cross spread technique is based on orthogonal geometry and is suitable for acquiring wide-azimuth data. Each intersection of a source line and a receiver line forms the center of a cross-spread. The dense sampling of the sources along the source line and of the receivers along the receiver line creates a dense single-fold areal coverage. The wide spread accesses created by seismic lines in the technique opens the doors to third party disturbances to production recording.

Cross spread technique of seismic prospecting is the configuration based on consistent orthogonal pattern of both receiver lines and source lines. At locations where infrastructural facilities such as oil well heads or underground pipelines interfere with the seismic lines, offset lines or skirtings are designed around consecutive obstacles. The angle of excursion of the skirting from the original line should range from $17^{\circ}$ to $34^{\circ}$. Around such intersection of lines with infrastructure or obstacle, a technical skirting designed about the obstacle would maintain separation distances between the structure and the offset source lines in terms of multiples of the receiver line spacing or source line spacing. Densification of the shot points is designed to cover the gap created between the scope of near-offset shots and near-mid offsets shots in order to build up subsurface coverage that will fill the gap created by the omission of source points within the area of infrastructural obstacle(s). Communities located within obstacle-areas might reject traversing of seismic lines across their sacred bushes and the solution will be to plan compensation source line offsets, which are designed as skirting around the obstacle zone. But this might leave minor "coveragelows" due to deficiency or loss of near-mid offset subsurface CDP's or bins or coverage. Seismic exploration in recent decades worldwide, has been 
faced with many and variable challenges. One of the major challenges is the occurrence of permit problems by host communities or their members to the free-flow of seismic data acquisition. The severity of the challenges varied with the location relative urban proximity, vegetation, significant mineral or geologic deposits or features, roads, heavy trucks on local roads, demand for youths' employment, and disagreements of non-acceptance of youths from one community in adjacent communities, spread of false information of negative impact of the exploration on certain aspect of the host community life, claim of contamination of groundwater by the dynamite explosives used in shooting operation, erroneous claim of pollution of air by company's fleet of vehicles and heavy generators, and generators. By implication, any of these factors can trigger off problems of interruption to exploration activity when permit procedures were violated, or when signedmemorandum of understanding (MOU) was violated by the seismic operator, when operational activities adversely impacted on the host communities and touching their source of livelihood sometimes of their creeks and rivers. Indicators of grievances include, blocking of access routes to seismic lines, disconnections of active-Receiver-line-cables and geophones to boxes/station units, theft of equipment, vandalizing of equipment, excavation and theft of buried $12 \mathrm{~V}$ motor batteries and power boxes, especially in the extensive receiver spread configurations, example of which is Sudan where Recording active spread was to the size of 16 Receiver Lines (figure2). On the other hand, the situation was different and more serious in Ethiopia due to stiff opposition of the Ogaden basin youths in the Somalian Region to the Ethiopian Federal Government efforts towards oil exploration. Hydrocarbon exploration projects were occasionally attacked in the region from 2007 to recent years, by some groups of violent youths noted for fighting against exploration activities within the country's hydrocarbon laden region.

Table 1: Safe Shooting Distances from Structures (IAGC)

\begin{tabular}{|c|c|c|}
\hline Objects $\mathrm{a}$ bo Protected & For Dyesmits Energy Source & Vibramr En ergy Son ree \\
\hline 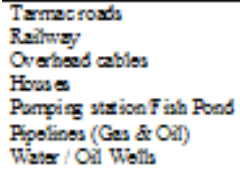 & $\begin{array}{l}50 \mathrm{~m} \\
50 \mathrm{~m} \\
50 \mathrm{~m} \\
150 \mathrm{~m} \\
150 \mathrm{~m} \\
150 \mathrm{~m} \\
200 \mathrm{~m}\end{array}$ & $\begin{array}{l}50 \mathrm{~m} \\
25 \mathrm{~m} \\
25 \mathrm{~m} \\
50 \mathrm{~m} \text { to } 150 \mathrm{~m} \text { depends on hot / block typo } \\
150 \mathrm{~m} \\
50 \mathrm{~m} \\
\text { In cess of no permivion to go to the nos rest off a }\end{array}$ \\
\hline
\end{tabular}

Study Area: This map pictures Niger Delta Seismic Acquired Blocks. The Nigeria component of the study sites consists mainly of the Niger delta.

Methodology:_During physical supervision of seismic operations, activities were captured and some constraints were encountered. Planned inspection visits to seismic lines in the fields were conducted and visits to field camps and Community Affairs and Permit Department of seismic crews were consistently monitored to check on the impact of permit problems on the production of various seismic projects. Operations' vehicles were allocated for monitoring both in Sudan/Ethiopia and in Nigeria especially for the purpose of timely intervention and resolution of community permit problems, road blockages, or seizure of seismic equipment or even severe cases of youths' seizure of explosives (dynamite/detonators) in the crave for employment or repair of damaged roads. More vehicles were used for line monitoring in Recording operations in Ethiopia and Sudan due to larger surface area coverage of active spread. The dimension of spread involving 16 Receiver Lines (Figure-2) Active spread of $(9 \mathrm{~km} \times 300 \mathrm{~m} \times 15 \mathrm{RL}$ Intervals $=40.5 \mathrm{Km}^{2}$.
In the field layout diagram shown below, the Receiver lines which run North-South and the Source Lines that run East-West provide multi-access to the arid desert. I). Cross Spread Receiver Lines, Trending NorthSouth II). Cross Spread Source Lines, Trending Continuous East-West

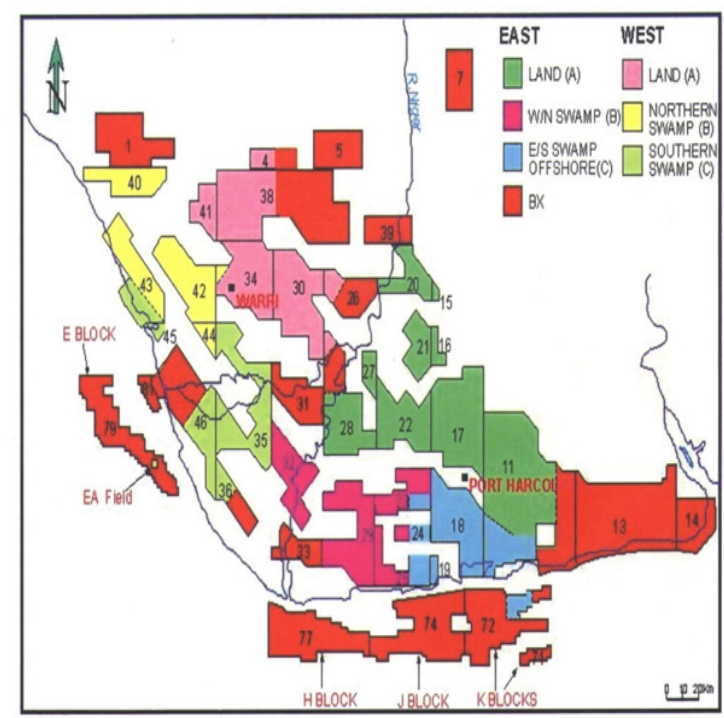

Fig 1: Map of Niger Delta showing various OML and OPL Blocks where Seismic data has been acquired 
The impact of heavy vehicles in Niger Republic, upper latitudes of West Africa, and the desert terrain of Ethiopia and Sudan were associated with copious "Dust-pollution" constituting thick brown clouds of dust that soared from the ground level to the sky. This situation along many parts of earth-roads in the active spread areas stirred up conflicts with other road users and host settlements. Sometimes, the brown clouds served as indicators of seismic vehicle locations within the cross spread continuous lines, which is contrary to Brick wall geometry where vehicle speed restriction is in place because of Source Line SL's end-of-line in the bush.

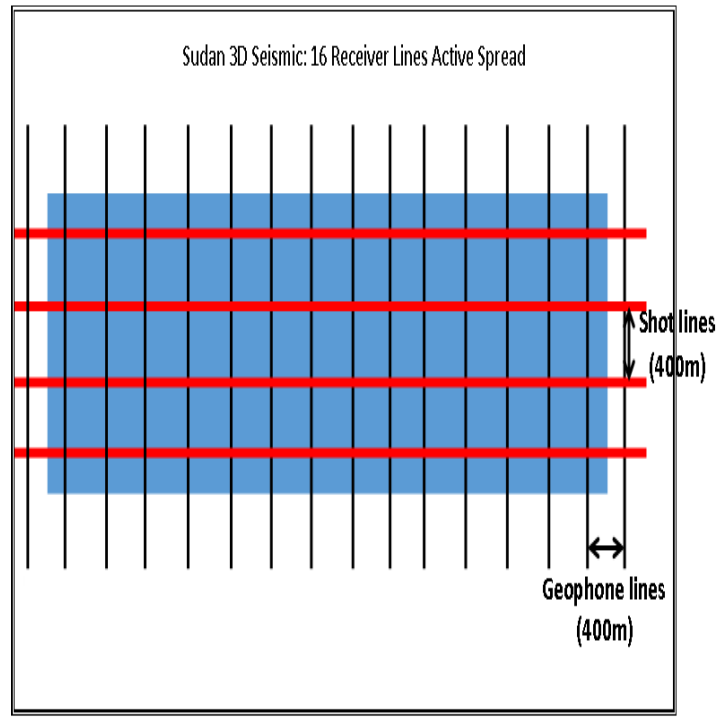

Fig-2:Cross Spread field configuration in Sudan 3-D Seismic Acquisition. Adapted Geophone lines configuration as synonymous with Receiver Lines. The Sudan oil fields, Fula South

To prevent damage of infrastructures or valuable facilities in the prospect area, such as block houses and water wells, oil wells, and pipelines, adherence is made to Nigeria's Department of Petroleum Resources' (DPR) specifications in Environmental Guidelines and Standards of Petroleum Industries in Nigeria (EGASPIN) shown in Table 1. There are permit procedures followed in order to arrive at the planning of shot points to implement the high resolution target of Optimal cross spread technique in hydrocarbon exploration. Every obstacle along the survey traverse of every source line is omitted thereon while suitable compensation source points are planned as laminar offsets, lateral offsets, and or skirting/smooth curve.

Lamina Offset:Cross-line shifts or North-South shifts: In this offset type, shot points that fall on an obstacle are moved to a new $\mathrm{Y}$ position while the $\mathrm{X}$-axis is fixed. The line number will bear the name of the new position as shown in the figure 3 below.

Lateral Offset: In-line \& Cross-line shifts: This is a composite offset method involving shifts in both X, Y axes. In this offset type, shot points that fall on an obstacle region are moved to new position with both coordinates changed. Specifically, the X-axis offset distance shall be $+/-500 \mathrm{~m}$ or its multiple in order to maintain a corresponding shot offset position (in Xdirection) from its original location. The new offset line name and shot point number will appear like as shown in figures3and 4 , below:

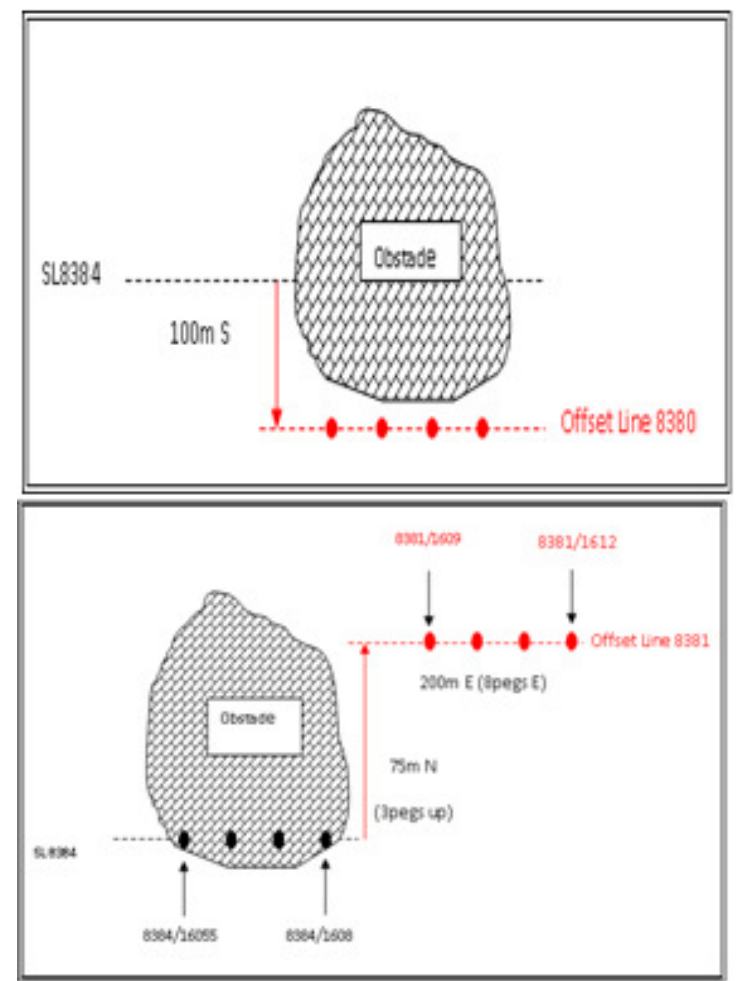

Fig 4: Showing lateral offset moved cross-line about the obstacle for Omission

Smooth Curve or Skirting: This is an offset type in which shot points obstructed by a large obstacle are smoothed around the obstacle with an inclination or deviation angle of $17 \geq \square \leq 27$ degrees, flattened at the crest or trough of the obstacle and returned to the base line with the same take off angle of $17-27$ degrees in a continuous manner, as shown in the skirting diagrams of figure 5 below. In the process of smoothing, it may affect other shot points at the inclination and declination points which ordinarily, could not have been moved in order to maintain a symmetrical shape. Smoothed curves shall not intersect another pre-designed grid line(s), thus the maximum distance (tape-out) for the crest or trough of 
any smooth curve shall be the distance between 2 source lines.

This offset option shall be applied in settlements, pipeline or oil well networks, forbidden or shrine areas, burial grounds, family tree (raffia palms) etc. This offset type shall take the first applicable priority in large obstacle areas.

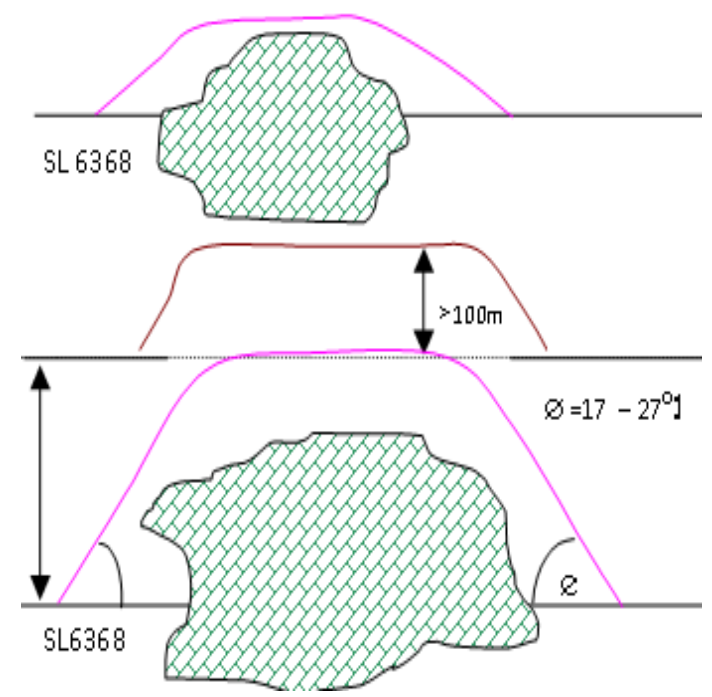

Fig 5: Showing Skirting of offsets about the Obstacle respecting deviation angle.

Receiver line offsets: When offsets are made on a receiver line, the original theoretical receiver name shall be maintained on the offset pegs, as in figure 6 below.

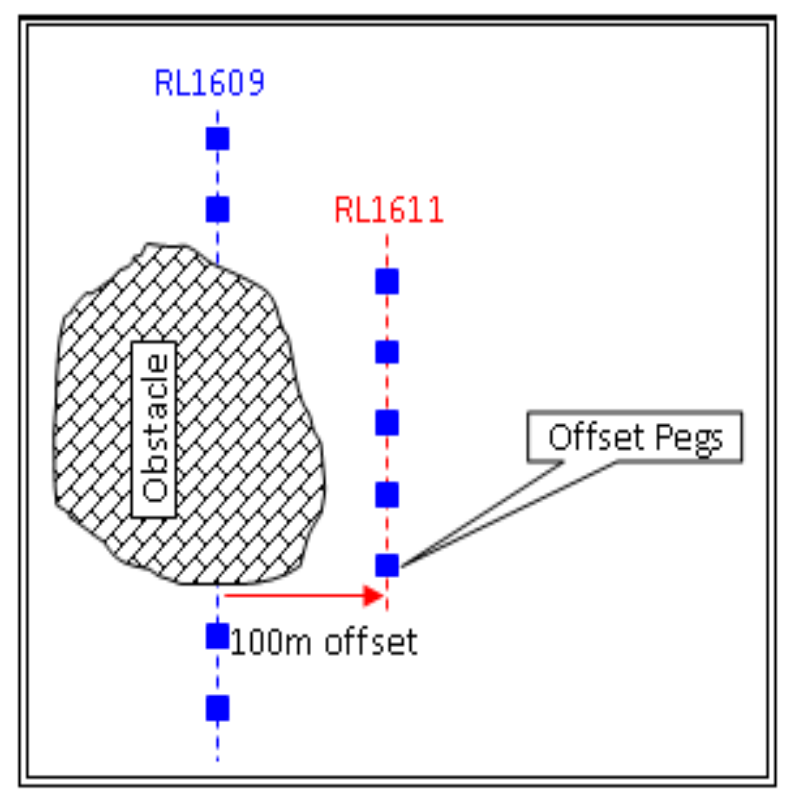

Fig 6: Showing Offsetting of a Receiver Line due to Obstacle to be omitted

\section{RESULTS AND DISCUSSION}

The percentage data in the Results was computed based on the number of permit cases reported during seismic acquisition (figure 7). Cases were tracked in the crew's Radio-books as well as Permit-men's "field notebooks". The cumulative field reports were evaluated.

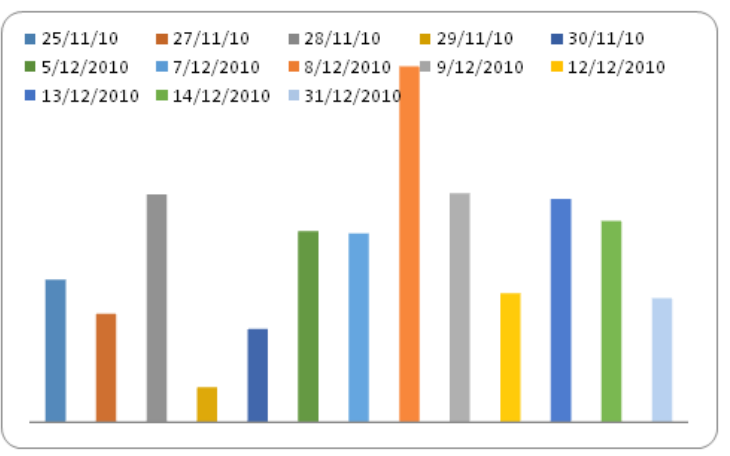

Fig 7: Chargeable Downtime (63.30hrs) due to community permit problems

Table 2 shows the various Permit Problems of Nigeria. The Permit problems were recorded as incidents that occurred and were resolved. The continuity and interconnection of the seismic lines in cross spread technique enhanced trafficking of more trucks, thus giving rise to more adverse consequences which hamper productivity, than the case of "Brick-wall" configuration or other prospecting techniques.

The Sudan seismic operations created multi-access to the remote areas of active spread, due to large extent of 16 Receiver Lines per unit active spread involved in the cross spread acquisition geometry (figure 2). There were disturbances to seismic lines by locals who ventured into remote portions of active spread for excavation and theft of buried $12 \mathrm{~V}$ batteries. In Niger delta, whenever seismic lines traversed community's sacred or forbidden bushes it attracted the grievance of the host community. Host communities signed permit to traverse their sacred bush through elders' procedural permission. The immediate consequence is usually blockage of roads to seismic lines, seizure, and vandalizing of recording line equipment, including geophones, power boxes and $12 \mathrm{~V}$ batteries. Indicators of grievances comprised, blockage of access routes to seismic lines, disconnection of active-spread, or Receiver-line-cables and geophones to boxes/station units, theft of equipment, vandalizing of equipment, excavation and theft of buried $12 \mathrm{~V}$ batteries and power boxes, especially in the extensive 16 (RL's) receiver active spreads of Sudan.

In the Niger delta of Nigeria, indicators of grievances are made up of blocking of access routes to seismic 
lines for survey crews, drilling crews, and recording crews, to jeopardize recording production. Permit problems indices also included vandalizing of recording line equipment, disconnections of Active spreads of Receiver Lines, cables and geophones links to boxes, and theft of line equipment. In two months of seismic investigation in the Niger Delta, there was a loss of $63 \mathrm{hrs}$ chargeable downtime due to permit problems (Figure 7).

The problem of Boko Haram insurgence in the NE of Nigeria, led to the termination of the seismic exploration ventures in the Chad Basin since 2014. The 3-D seismic acquisition programs in the Chad Basin were put on indefinite suspension due to security problems in the area. The flat topography and openness of the terrain in the Chad Basin area provided easy access to the Boko-Haram to attack and burn down operations trucks and jeopardized further seismic surveys in the basin.

In the effort to prevent damages to infrastructure by different energy sources, dynamite or vibroseis, the structures which are regarded as obstacles are planned or designed and omitted but compensated for with various types of offset shots. The contribution of manifold offsets culminates into required multiplicity that enhances the high resolution of the subsurface imaging (as CDP's or CMP's). The orthogonal traverse associated with the cross spread technique runs into infrastructures via the regional trend of the seismic lines, and thereby kicks-off the permit problems in diversities.

The propensity of Permit problems tend to get complicated with creation of multiple accesses through the activation of source and receiver lines of orthogonal continuity. The continuity and interconnectivity of the seismic lines in cross spread technique enhanced trafficking of trucks of third party users, and criminals, thus resulting in more limiting consequences than in brick-wall technology or other techniques with interlocking bushes. In the effort to prevent damages to infrastructure by different energy sources, dynamite or vibrators, the structures which are regarded as obstacles are programmed for omission and but compensated for with various types of offset shots that still running in orthogonal straight lines averting permit problems. The contribution of manifold offsets yields the required multiplicity that enhances the resolution of the subsurface imaging (CDP's or CMP's).

In Nigeria, community permit grievances often culminated in blockage of roads to seismic lines for survey crews, drilling crews, and recording crews, all targeted to jeopardize Recording production. Disconnection of Active spreads of Recording operations, via cables and geophones, vandalizing the line equipment, and sometimes theft of equipment are also increased with the techniques with concomitant multiple access.

Conclusion:_The Permit problems got complicated by multiple accesses created by the occurrence of source and receiver lines of the orthogonal continuity of the optimal cross spread technique. The continuity and interconnectivity of the seismic lines in cross spread technique enhanced trafficking of trucks, third party users, and criminals, thus yielding more limiting consequences than in brick-wall technology or other exploration techniques that have interlock of bushes.

\section{REFERENCES}

Furon, R (1963). The Geology of Africa. Oliver \& Boyd, Edinburgh and London, 377

IAGC (2005). International Association of Geophysical Companies (IAGC) Manual.Ed (3), 578

Nwachukwu, JA (1999). Seismic Acquisition in the Niger Delta - Past, Present, and Future. Nigerian Association for Petroleum Explorationists (NAPE). (An Affiliate of the American Association of Petroleum Geologists, AAPG). Vol 2, 211-217

NPL (20 10). Courtesy Of Exploration Department, Newcross Petroleum Limited Nig

Olaide IA (2013). Boko Haram Insurgency in Nigeria: Its Implication and Way Forwards toward Avoidance of Future Insurgency. International Journal of Scientific and Research PublicationsVol. 3, No.11

Robinson, EA; Treitel, S (1980). Geophysical Signal Analysis. Prentice-Hall Inc. NJ. 466

Telford, WM; Geldart, LP; Sheriff, RE (1976). Applied Geophysics. Ed (3), NY, 2124

Van de Rijzen, MJ, Gisolf, A., Verschuur, DJ (2004). Infilling of sparse 3D data for 3D focusing operator estimation, Geophysical Prospecting, 52, 489-507

Vermeer, GJO (2002). 3-D Seismic Survey Design, Society of Exploration Geophysicists (SEG), $2^{\text {nd }}$ Edition 